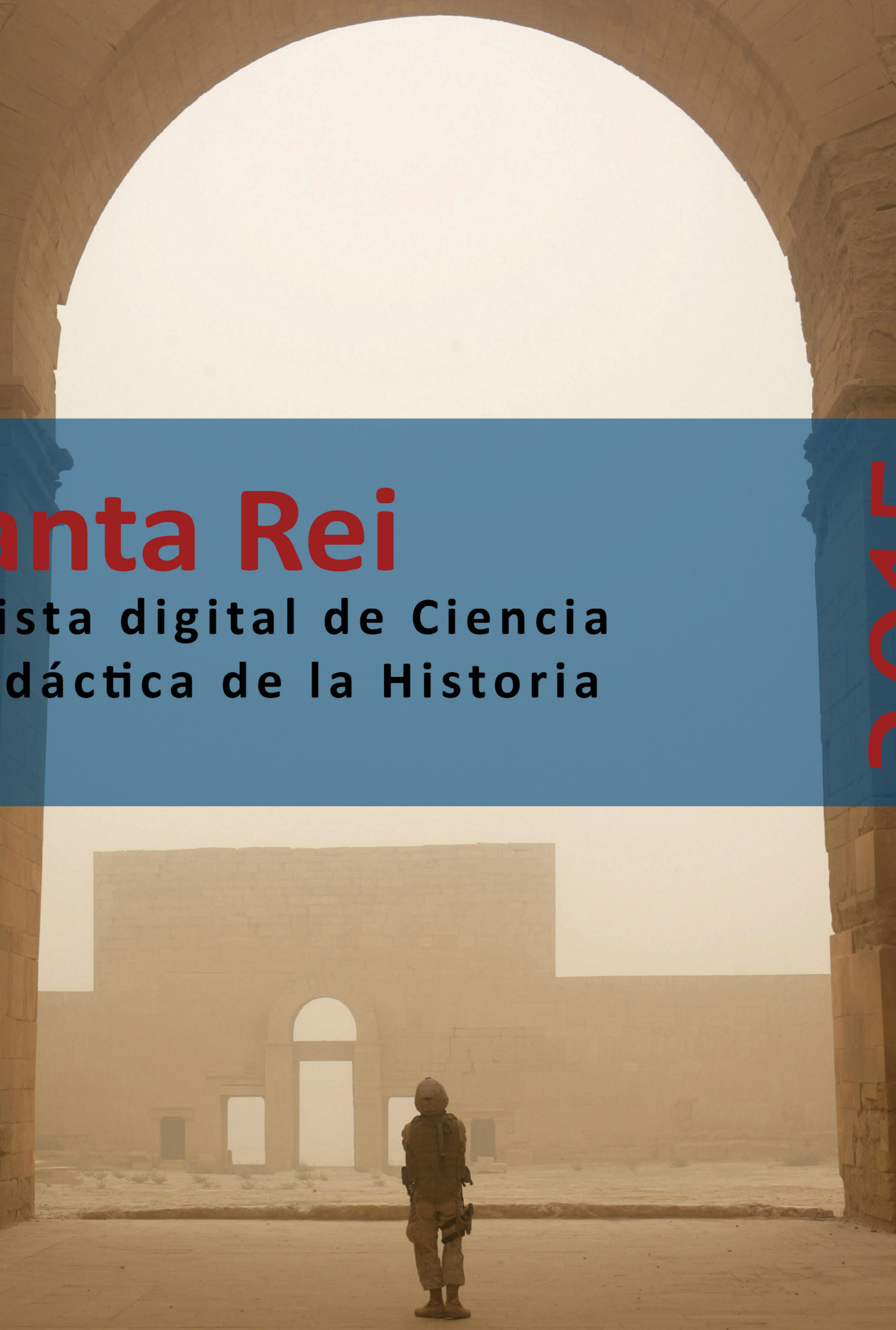

Revista digital de Ciencia y Didáctica de la Historia 


\section{Panta Rei \\ Revista Digital de Ciencia \\ y Didáctica de la Historia}

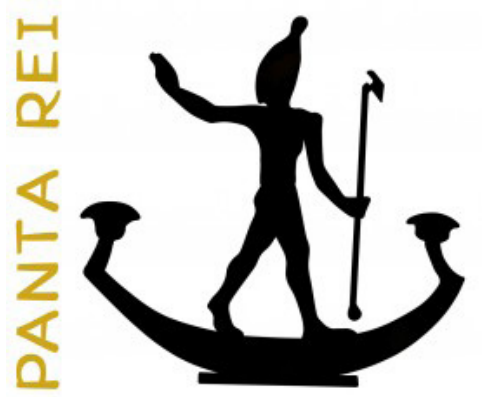

\section{5}

Revista anual

Fecha de inicio: 1995

Revista Panta Rei. pantarei@um.es

Edita:

Centro de Estudios del Próximo Oriente y la Antigüedad Tardía - CEPOAT

Edificio Universitario Saavedra Fajardo.

Universidad de Murcia

C/ Actor Isidoro Máiquez, 9

30007 - MURCIA - ESPAÑA

Teléfono: (+34) 868883890

cepoat@um.es

Web: www.um.es/cepoat/pantarei

Edición 2015

ISSNe: 2386-8864

ISSN: 1136-2464

Depósito legal: MU-966-1995
cepoAt

UNIVERSIDAD DE MURCIA centro de estudios del próximo oriente y la antigüedad tardía

En Portada: Ruinas de Hatra (Irak) (Fotografía de: Lance Cpl. Albert F. Hunt, U. S. Marine Corps).

Responsables de los textos: Sus autores.

Responsable de la presente edición: Consejo Editorial Panta Rei. 


\section{CONSEJO DE REDACCIÓN}

\section{Coordinador editorial}

Egea Vivancos, Alejandro

[Didáctica de las Ciencias Sociales, UMU]

\section{Editores}

Botí Hernández, Juan Jesús

[CEPOAT, UMU]

Meseguer Gil, Antonio José

[CEPOAT, UMU]

Sáez Giménez, David Omar

[CEPOAT, UMU]

Sánchez Mondéjar, Celso Miguel

[CEPOAT, UMU]

\section{Secretaria}

Arias Ferrer, Laura

[Didáctica de las Ciencias Sociales, UMU]

\section{Responsable informático}

Martínez García, José Javier

[CEPOAT, UMU]

\section{Traducción y corrección lingüística}

Martínez Martínez, Cristina

[Sociedad Española de Lenguas Modernas]

\section{CONSEJO ASESOR}

Albero Muñoz, M. ${ }^{a}$ del Mar [H. ${ }^{a}$ del Arte, UMU]

Chapman, Arthur

[History Education, UCL, Reino Unido]

Cobacho López, Ángel

[Derecho, UMU]

Egea Bruno, Pedro M. ${ }^{\text {a }}$

[Historia Contemporánea, UMU]

García Atienzar, Gabriel

[Prehistoria, UA]

González Monfort, Neus

[Didáctica de las Ciencias Sociales, UAB]

Haber Uriarte, María

[Prehistoria, UMU]

Irigoyen López, Antonio

[Historia Moderna, UMU]

Mahony, Simon

[Digital Humanities, UCL, Reino Unido]

Marsilla de Pascual, Francisco Reyes

[Técnicas historiográficas, UMU]

Miralles Maldonado, José Carlos

[Filología Clásica, UMU]

Molina Gómez, José Antonio

[Historia Antigua, UMU]

Noguera Celdrán, José Miguel

[Arqueología, UMU]

Pérez Molina, Miguel Emilio

[Filología Clásica, UMU]

Prados Martínez, Fernando

[Arqueología, UA]

Sánchez Ibáñez, Raquel

[Didáctica de las Ciencias Sociales, UMU]

Sancho Gómez, Miguel Pablo

[Educación, UCAM]

Vilar García, María José

[Historia Contemporánea, UMU] 

Artículos

El patrimonio arqueológico iraquí y su destrucción a lo largo del tiempo.

Fernando Espejel Arroyo.

Tacita Muta y el silencio femenino como arma del patriarcado romano.

Sara Casamayor Mancisidor.

Espartaco en la arqueología.

Juan Luis Posadas.

La batalla de Andagoste.

Luis Amela Valverde.

Las trabas para una formación arqueológica inclusiva.

Ana Samaniego Espinosa.

Repensando las narrativas nacionales: Un análisis del origen, transmisión e influencia en el aprendizaje histórico.

César López Rodríguez

El profesor como predicador, provocador y ermitaño. Un pre-texto para pensar las tareas de la didáctica de la historia.

Enrique Ibáñez Rojo

Entrevista

Evaluando el desarrollo de la competencia histórica en la enseñanza de la Historia en España. Entrevista a Jesús Domínguez Castillo.

María José Morales Rodríguez.

Reseñas

II Congreso de Jóvenes Investigadores del Mundo Antiguo de la Universidad de Murcia.

Pedro David Conesa Navarro y Juana M. ${ }^{a}$ Martínez Molina.

II Jornadas Internacionales de Didáctica de la Historia.

Eusebio Manuel Vidal Abellán.

Dölger, F. J. (2015). La luz de Cristo. Madrid: Ediciones Encuentro. 98 págs.

Alejandro Ruiz Sánchez.

Cooper, H. (ed.) (2013). Teaching History Creatively. Londres: Routledge. 185 págs.

Marta Gil de Sola Bellas.

El arte paleolítico en El Carnicero de Chabrol.

Alberto Lombo Montañés.

Normas de publicación/Publishing rules 



\title{
Las trabas para una formación arqueológica inclusiva
}

\author{
The obstacles to an inclusive archaeological training
}

Ana Samaniego Espinosa ${ }^{1}$

Universidad de Alicante

Recibido: 20/01/15

Aceptado: 09/08/15

Para citar este artículo: Samaniego Espinosa, A. (2015). Las trabas para una formación arqueológica inclusiva. Panta Rei. Revista Digital de Ciencia y Didáctica de la Historia, 63-75.

ISSNe: 2386-8864

DOI: http://dx.doi.org/10.6018/pantarei/2015/5

\section{Resumen}

La formación arqueológica se realiza en España, principalmente, en las universidades ya sea en sus aulas o en una excavación. Si añadimos la palabra inclusiva estamos hablando de formar a arqueólogos con algún tipo de discapacidad.

Este artículo reflexiona sobre los factores que intervienen en la actualidad para la formación arqueológica a estudiantes con discapacidad. Se trata la legislación vigente sobre igualdad y el derecho a la formación. La figura de la Universidad como institución que une a la diversidad para detectar y potenciar los talentos diferentes que necesita la sociedad.

Se consideran los factores que intervienen en la formación práctica arqueológica y su didáctica por parte del profesorado y finalmente se reflexiona sobre las posibles trabas que la propia tradición académica arqueológica introduce en dicha formación.

\section{Palabras clave}

Accesibilidad, formación, arqueología, inclusión, universidad.

\section{Abstract}

In Spain, the archaeological instruction is carried out, mainly, at universities, either in the classrooms or at excavations. If the word inclusive is added, we are talking about training archaeologists with some sort of disability.

This article reflects on the elements which take part in the archaeological training of students with disabilities at present. It deals with the current legislation on equality, and the right to academic training. It also considers the university as the institution which connects the diversity, to detect and strengthen the different talents that society needs.

The elements which take part in the practical archaeological training, and its teaching by the faculty are considered. Finally, the present paper reflects on the possible obstacles that the academic archaeological tradition itself introduces in the mentioned training.

\section{Key Words}

Accessibility, training, Archeology, inclusion, University.

1 Para contactar con la autora: Ana Samaniego Espinosa. Dpto. Prehistoria, Arqueología, Historia Antigua, Filología Griega y Filología Latina. Facultad de Filosofía y Letras. Universidad de Alicante. 03080 Alicante. España. anasamaniegoespinosa@gmail.com. 


\section{Introducción}

Cuando nos referimos a una formación arqueológica inclusiva hablamos de una formación impartida en una universidad preocupada, evidentemente, por el aprendizaje de sus alumnos y alumnas, y que dispone de los recursos necesarios para posibilitar que todos aprendan, o los crea, si no los tiene. Pero también hablamos de una universidad, y de un sistema educativo, que acoge y valora a todos, sin exclusiones. Y no como una concesión, sino como una cuestión de derecho, de justicia y de necesidad.

Si como formación inclusiva nos centramos en el alumnado con diversidad funcional, hablamos de personas con algún grado de discapacidad legalmente reconocida que supone el derecho a solicitar apoyos que faciliten su integración. Pero también hablamos de alumnos con limitaciones no reconocidas pero cada vez más comunes en la sociedad como la dislexia o el daltonismo, por citar las más habituales y conocidas.

La realidad es que la formación arqueológica para alumnas y alumnos con discapacidad en España no siempre está garantizada por problemas en accesibilidad urbanística, arquitectónica o económica pero también hay que tener en cuenta las trabas que se introducen desde la tradición académica arqueológica al distinguir entre alumnos.

Descubrir las trabas académicas que dificultan una formación arqueológica inclusiva es hacer que la Arqueología continúe en su proceso evolutivo y no se pierda el talento y la motivación de toda la sociedad para la que trabajamos.

Recapacitar sobre la formación arqueológica que se imparte hoy en día en España a estudiantes con discapacidad, es poner las cartas sobre la mesa de un juego al que pocos quieren jugar; o como dicen algunos colegas arqueólogos, es como reflejar la realidad en un espejo que provoca sensibilidades donde muchos temen verse. No se trata de criticar de forma irónica o destructiva la labor que tan magníficamente se realiza por tantos y tantos profesionales. Se trata de seguir profundizando en detalle, siendo honestos con nuestro trabajo y concretamente con una de las múltiples áreas en las que un arqueólogo puede desempeñar su trabajo, la formación.

Dicha formación arqueológica no sólo se imparte en las aulas universitarias o en las excavaciones, sino también a través de los sistemas de divulgación y difusión tan necesarios en nuestra disciplina y que, en la actualidad, mínimamente considera las necesidades de las personas con diversidad funcional ya sean alumnos, profesionales o población general con alguna discapacidad.

Existe legislación y normativa internacional, nacional y autonómica que habría que revisar porque adolece de dos características. La primera es que no sanciona su falta de cumplimiento y la segunda es que solo define los términos, sin profundizar en los procedimientos y sin indicar unas pautas mínimas asumibles.

Aunque la actitud social y de los poderes públicos sea la de crear el marco legal necesario y también el tener la voluntad para conseguir una igualdad plena de oportunidades, la realidad es otra bien distinta.

\section{Breve pluralidad terminológica sobre la discapacidad}

Creo necesario introducir un apartado para aclarar los conceptos que se van a manejar a lo largo de este trabajo porque son habituales si estás involucrado en temas de discapacidad pero no lo son en arqueología. Hay que incorporar a nuestro vocabulario la terminología correcta porque a lo largo de la historia el trato dado a las personas con discapacidad ha ido variando y se ha ido utilizando diversa terminología para nombrar y agrupar a las personas con discapacidad. Aunque algunos de estos términos contaban en sus orígenes con cierto valor científico, hoy en día son claramente peyorativos e inadecuados, empleándose con etiquetas que significan tanto una pérdida funcional como una carencia de valor. 
Hoy en día se plantea la necesidad de utilizar lenguajes integradores que eliminen toda connotación peyorativa y vean a la persona con discapacidad más allá de las etiquetas del "dis", potenciando todas las capacidades y apostando por la diversidad funcional. Término que se empieza a utilizar sustituyendo al de discapacidad. En este trabajo se utilizará el de persona con discapacidad por ser el más común, aunque también el de diversidad funcional por ser más positivo e inclusivo y hacer hincapié en la diversidad.

Espinosa y Bonmatí (2013) enfatizan sobre la necesidad de evitar términos victimistas o emotivos. No son personas que necesiten algún tipo de compasión. Así, indica que "es mejor hablar de "personas sin limitaciones (o problemas) funcionales» que de "personas normales», pues el lenguaje no inclusivo refuerza los aspectos negativos, no reconoce la aportación de las personas con discapacidad a la sociedad, y las posiciona en un estatus inferior al resto." (Espinosa y Bonmatí, 2013, p. 35).

Un paseo detenido por el campus de cualquier universidad española puede darnos una idea de la escasa capacidad inclusiva que existe, entendiendo como inclusiva la capacidad de incluir, o lo que es lo mismo de no discriminar, de tener en cuenta al total de la sociedad, alumnos, profesores o cualquier persona que trabaje en una universidad. Distingo inclusión de integración, en tanto en cuanto considero que la integración consiste en que es el individuo quien se adapta al entorno con los apoyos que necesite. Sin embargo, la inclusión se produce cuando el entorno elimina barreras y permite la participación total de la sociedad, con el objetivo de evitar que la discapacidad o diversidad funcional pueda suponer un problema.

En la actualidad no existe una definición clara del término "integración", de ahí que se utilice con diversos significados. De acuerdo con el Diccionario Enciclopédico de Sociología (Hillmann, 2005), la integración es la "denominación con que se conocen en sociología los procesos de incorporación y asimilación [...]". En la actualidad el más empleado es el de inclusión, ya sea por moda, contexto social, político, pedagógico, o por simple evolución al de integración (Pérez, 2010). Consideramos que la inclusión va más allá porque responde a las necesidades de todos y no necesita tener en cuenta la integración porque le viene dada.

Otro concepto que necesita de su aclaración para el correcto entendimiento de este trabajo es el de accesibilidad. Al hablar de accesibilidad a todos nos viene a la cabeza una persona en silla de ruedas, pero es un concepto que va más allá porque la limitación de capacidades o facultades es algo que nos ocurre a todos a lo largo de nuestra vida, de forma temporal o permanente. Un ejemplo muy sencillo, las personas que tenemos una limitación visual necesitamos el apoyo de las comúnmente conocidas gafas. En definitiva, la accesibilidad no es más que la cualidad de facilitar el acceso físico e intelectual en cualquier medio.

Por último el concepto de diseño para todos, su objetivo es simplificar la vida de todas las personas, haciendo que entornos y productos sean utilizables y comprensibles para un mayor número de personas. Este concepto es muy utilizado principalmente en urbanismo, arquitectura y comunicación en cualquier medio físico o virtual.

En cuanto a los distintos tipos de discapacidades, se pueden clasificar en mentales, sensoriales y motrices. La discapacidad mental incluye la intelectual (orientación, ansiedad, miedo, toma de decisiones y dislexia, entre otras) y psíquica (reacciones ante situaciones) y se refiere a la limitación de habilidades que tiene la persona para aprender a funcionar en su vida diaria. Sobre las discapacidades sensoriales hay que indicar que es aquella provocada por una limitación en la función de los cinco sentidos, la vista, el oído, el olfato, el gusto y el tacto. La discapacidad motriz se refiere a las deficiencias producidas por limitaciones que pueden afectar a la movilidad, al habla o a la gesticulación sin que signifique discapacidad intelectual.

En definitiva, incluir es tanto como poner las cosas fáciles a todo el mundo. 


\section{La cruda realidad de la formación universitaria inclusiva en cifras}

Cuando hablamos de la lamentable tasa de desempleo que hay en España en la actualidad hay que considerar que la tasa de desempleo de las personas con discapacidad supone 8,1 puntos más que el conjunto de la población activa total, según el último informe publicado del Instituto Nacional de Empleo (INE) ${ }^{2}$ del 2012. Este informe también indica la importancia que tiene la formación como variable que ayuda a aumentar la tasa de actividad a medida que se incrementa el nivel de formación.

Pero la realidad formativa y en concreto la universitaria revela la elevada cifra de abandono entre los estudiantes con discapacidad. EI II Estudio de Universidad y Discapacidad ${ }^{3}$ indica que de las 59 universidades estudiadas (públicas y privadas) son 17.702 los alumnos matriculados con discapacidad, lo que supone un $1,3 \%$ de la comunidad universitaria. De éstos, el $0,9 \%$ cursan sus estudios en universidades con modalidad presencial y de ellos sólo el 5,4\% termina sus estudios universitarios, frente al $18,7 \%$ de los estudiantes sin discapacidad, según el informe del OED de $2012^{4}$.

Es decir, los estudiantes con discapacidad superan las pruebas de acceso a la universidad pero la mayoría no concluye sus estudios. Reflexionando sobre los posibles motivos que pueden llevar a que un estudiante con discapacidad abandone sus estudios, además de los motivos comunes a los que no tienen restricciones, analizamos a continuación las trabas que la propia academia introduce en la formación de estos alumnos y alumnas.

\section{Los impedimentos de una formación arqueológica inclusiva}

¿Cuáles son las dificultades que existen en España actualmente? A continuación, vamos a analizar las dificultades más palpables que existen en la actualidad para una formación arqueológica para alumnos con discapacidad desde el punto de vista del entorno físico.

Es necesario mencionar que también existe amplia normativa sobre accesibilidad urbanística y arquitectónica. En España los criterios de accesibilidad están regulados por el Real Decreto 314/2006, de 17 de marzo, que aprueba el Código Técnico de la Edificación (BOE 28/03/2006). En la sección DB-SUA: Seguridad de Utilización y Accesibilidad se definen los criterios básicos para reducir todo riesgo de utilización y garantizar una plena accesibilidad. Además, existe distinta legislación como la Ley 3/1996, de 24 de septiembre, sobre Accesibilidad y Supresión de Barreras arquitectónicas, urbanísticas y de la Comunicación. O también las normas UNE cuya aplicación voluntaria garantiza unos niveles de calidad y seguridad 5 .

Siguiendo con las recomendaciones, hay que considerar las que se realizan desde los observatorios sobre discapacidad, tanto a nivel estatal ${ }^{6}$ como los de cada una de las universidades

2 Recuperado de: http://www.ine.es/jaxi/menu.do?type=pcaxis\&path=/t22/p320/serie\&file=pcaxis

3 Este informe lo ha realizado la Fundación Universia junto al Comité Español de Representantes de Personas con Discapacidad (CERMI) para dar a conocer el estado actual del grado de inclusión de las personas con discapacidad en el sistema universitario español relativo al curso académico 2013/2014.

4 Observatorio Estatal de la Discapacidad (OED). Recuperado de: http://www.sepe.es/contenido/conocenos/ publicaciones/pdf/IMT_2013_Datos_2012_Estatal_Discapacitados.pdf

5 Las referidas a la accesibilidad son UNE 41500:2001 (Accesibilidad en la edificación y el urbanismo. Criterios generales de diseño), la norma UNE 41510:2001 (Accesibilidad en el urbanismo), la UNE 41520:2002 (Accesibilidad en la edificación. Espacios de comunicación), UNE 41522:2001 (Accesos a los edificios) y UNE 41523:2001 (Espacios higiénico-sanitarios); también nos interesan otras, como las UNE 41524:2010 (Reglas generales de diseño para la accesibilidad de la edificación) y las UNE 23034 y 23035 (Señalización e lluminación, respectivamente, de los medios de evacuación), además de las ya citadas UNE 170001-1 y 2 , y 170002.

6 Recuperado de: www.msssi.gob.es/ssi/discapacidad/serviciosPersonasDiscapacidad/ 
españolas y cuyas recomendaciones se centran específicamente en el entorno universitario. A modo de ejemplo se puede consultar los proyectos desarrollados desde el Observatorio Universidad y Discapacidad de la Cátedra de Accesibilidad de la Universidad Politécnica de Cataluña que se desarrollan conjuntamente con la Fundación ONCE?.

Pero la realidad es que la aplicación de esta legislación suele ser obviada por algunos arquitectos o incluso interpretada como un "problema más", como ocurre normalmente a la hora de tratar un elemento patrimonial. Esta actitud se produce cuando tratan de adoptar soluciones alternativas (que no dejan de suponer una discriminación) en lugar de pensar en soluciones inclusivas.

Resulta paradójico comprobar que informes sobre el grado de inclusión de las universidades españolas indiquen "Casi la totalidad de las universidades (92\%) cuentan con criterios de accesibilidad en la adquisición o alquiler de nuevas instalaciones" ${ }^{\text {. }}$. Un paseo detenido por el campus de cualquier universidad española puede darnos una idea de la escasa capacidad inclusiva que existe. Los criterios de accesibilidad y el diseño para todos son inexistentes. Por citar sólo los casos más visibles, hay que hacer mención a las puertas imposibles de maniobrar por personas con movilidad reducida, aseos no accesibles o aulas donde los sistemas audiovisuales impiden la correcta visualización y audición por la totalidad del alumnado, con o sin discapacidad.

En definitiva, la accesibilidad total es una utopía pero no es todo o nada. Es un proceso continuo que debe tener fases programadas para acometer las acciones de accesibilidad e inclusión progresivamente. La accesibilidad es una característica que otorga calidad y que repercute en la comodidad y seguridad de todas las personas. Hay que reconocer el esfuerzo que desde algunas universidades se hace para la sensibilización sobre estos menesteres. La existencia de departamentos u observatorios dedicados en exclusiva, generan programas como el campus accesible e igualitario de la Universidad de Alicante ${ }^{9}$.

\section{Otros obstáculos en la práctica arqueológica para personas con discapacidad}

Un arqueólogo es historiador. Un buen historiador necesita saber de arqueología para poder construir información y datos arqueológicos a partir de las fuentes materiales. Por tanto, los estudios de Historia han de ser inclusivos necesariamente en arqueología.

González (2013) cita a Everill (2007) al referirse a la importancia de la formación práctica. La enseñanza práctica de la arqueología parte desde la universidad ante la necesidad de ajustar los contenidos teóricos impartidos en el aula con las destrezas y conocimientos prácticos que necesariamente se han de adquirir con el trabajo de campo.

La realidad es que esas destrezas son adquiridas gracias al interés de los propios alumnos en participar como voluntarios en las campañas organizadas por los profesores arqueólogos para su propia investigación, en campos de trabajo o en cursos específicos organizados también por empresas privadas, entre otros sistemas de aprendizaje. Pero ¿todos los alumnos pueden ir a una excavación? Sin entrar a evaluar los requisitos que cada profesor estipula a los alumnos que le acompañarán en las campañas, la realidad es que aquellos que tienen alguna discapacidad lo tienen más complicado.

La arqueología implica subir montañas, bajar a cuevas y picar dentro de sondeos pero también existen diversas tareas prácticas que no son únicamente la propia excavación. Se necesita de muchas funciones especializadas de campo y de gabinete. La aplicación de los conocimientos de diversas ciencias para que una investigación y su posterior difusión y divulgación llegue a buen puerto. Se trata de trabajar en un equipo de profesionales donde cada uno aporte lo mejor de sus

7 Recuperado de: http://www.catac.upc.edu/index.php/es/oud

8 El dato está evaluado en el Estudio sobre el grado de inclusión del sistema universitario español respecto de la realidad de la discapacidad. Fue elaborado en 2011 por la Fundación Universia. Recuperado de: http:// www.fundacionuniversia.net/actualidad/noticias/detalleNoticias-2822.html

9 Recuperado de: http://blogs.ua.es/campusaccesiblecampusigualitario/

Panta Rei (2015), 63 - 75 
cualidades sin considerar sus limitaciones. Quizás, sería necesario que la comunidad científica arqueológica realizara un nuevo ejercicio de apertura para replantearse, si quiera, si es necesario definir las características para ser un buen arqueólogo y si lo es, redefinir las actuales por ser limitadas. Como decía anteriormente la arqueología se trata de una ciencia multidisciplinar donde la especialización y el buen hacer deben ser los únicos factores para marcar la diferencia.

Entonces, ¿un licenciado de historia con discapacidad y orientación en arqueología podría ser un buen arqueólogo? Para demostrar su afirmación, se ha realizado un pequeño estudio tomando el síndrome de Asperger como modelo, debido a que se trata de una de las discapacidades más habituales en la rama de humanidades de las universidades españolas. Según la psiquiatra inglesa Wing (1981), el síndrome de Asperger tiene en común una discapacidad en el desarrollo de la interacción social, la comunicación y la imaginación.

¿Qué tareas arqueológicas puede realizar una persona con síndrome de Asperger? Para responder a esta pregunta vamos a comparar las facultades físicas y cognitivas que serían necesarias para la realización de una tarea arqueológica como el inventario y la catalogación de piezas (Figura 1), con las capacidades generales de una persona con síndrome de Asperger (Figura 2).

\begin{tabular}{|c|c|}
\hline Tareas de una excavación tipo & Necesidades físicas y cognitivas \\
\hline \multicolumn{2}{|c|}{ Antes de la excavación. Necesidades básicas: Trabajo en equipo. } \\
\hline $\begin{array}{l}\text { ¿Para qué se quiere excavar? Definir el } \\
\text { proyecto. }\end{array}$ & $\begin{array}{l}\text { Entender y comunicar información detallada. } \\
\text { Habilidades sociales. }\end{array}$ \\
\hline $\begin{array}{l}\text { Buscar información del lugar: cartografía, } \\
\text { análisis SIG, fotografías, uso de drones, } \\
\text { documentación en archivos y bibliotecas. }\end{array}$ & $\begin{array}{l}\text { Manejo de ordenador. Desplazamiento físico. } \\
\text { Entender material escrito y comunicar } \\
\text { información. Habilidades sociales. }\end{array}$ \\
\hline ¿Dónde se va a excavar? & Capacidad de análisis. \\
\hline Protocolos de intervención & Toma de decisiones. Resolución de problemas. \\
\hline \multicolumn{2}{|c|}{ Durante la excavación. Necesidades básicas: Visión. } \\
\hline Montar cuadrícula & Fuerza del cuerpo y caminar. Trabajo en equipo. \\
\hline Quitar sedimento & $\begin{array}{l}\text { Movimiento de la mano/ muñeca y del cuerpo } \\
\text { superior. Ponerse en cudillas o sentado en el } \\
\text { suelo. }\end{array}$ \\
\hline Retirar / leer estratos & $\begin{array}{l}\text { Movimiento de la mano / muñeca y del cuerpo } \\
\text { superior. Ponerse en cudillas o sentado en el } \\
\text { suelo. Capacidad de análisis. Trabajo en equipo. }\end{array}$ \\
\hline $\begin{array}{l}\text { Documentación: Cotas, dibujos, fichas, } \\
\text { fotografias }\end{array}$ & $\begin{array}{l}\text { Movimiento de la mano/ muñeca y del cuerpo } \\
\text { superior. Habilidad numérica. Dibujo. Manejo de } \\
\text { cámara fotográfica. Trabajo en equipo. }\end{array}$ \\
\hline Recogida selectiva de muestras & $\begin{array}{l}\text { Destreza para coger/dejar pequeños objetos, } \\
\text { bolsas. Escribir. }\end{array}$ \\
\hline \multicolumn{2}{|l|}{ Después de la excavación } \\
\hline Lavado / siglado & $\begin{array}{l}\text { Movimiento de la mano / muñeca y del cuerpo } \\
\text { superior. Escribir. Trabajo independiente. }\end{array}$ \\
\hline Inventario y catalogación & $\begin{array}{l}\text { Ordenar y catalogar. Capacidad de análisis. } \\
\text { Escribir. Trabajo independiente. }\end{array}$ \\
\hline Bases de datos & $\begin{array}{l}\text { Manejo de ordenador. Entender información } \\
\text { escrita. Trabajo independiente. }\end{array}$ \\
\hline Procedimiento estadístico. & $\begin{array}{l}\text { Manejo de ordenador. Cálculo numérico. } \\
\text { Entender información escrita. Trabajo } \\
\text { independiente. }\end{array}$ \\
\hline Elaborar informe / memoria & $\begin{array}{l}\text { Manejo de ordenador. Entender información } \\
\text { escrita. Escribir. Capacidad de análisis. Trabajo } \\
\text { independiente. }\end{array}$ \\
\hline Divulgar / difundir & $\begin{array}{l}\text { Manejo de ordenador. Entender lo escrito. } \\
\text { Escribir. Trabajo en equipo/independiente. }\end{array}$ \\
\hline
\end{tabular}

Figura 1: Tareas de un proyecto arqueológico tipo y sus necesidades físicas y cognitivas. 


\begin{tabular}{|c|c|}
\hline Debilidades & Amenazas \\
\hline $\begin{array}{l}\text { - Preocupado obsesivamente si no saben } \\
\text { qué esperar. } \\
\text { - Miedo a lo desconocido. } \\
\text { - Dificultad de ponerse en el lugar del otro } \\
\text { - Tendencia al aislamiento. } \\
\text { - Tendencia al egocentrismo } \\
\text { - Dificultades para reconocer y expresar } \\
\text { emociones propias y en otros. }\end{array}$ & $\begin{array}{l}\text { - El estrés, la autoestima baja, la } \\
\text { depresión, la falta de flexibilidad } \\
\text { - El cansancio físico. } \\
\text { - La sobrecarga sensorial por factores } \\
\text { ambientales. } \\
\text { - Las sorpresas. Los cambios. } \\
\text { - El contacto físico. }\end{array}$ \\
\hline Fortalezas & Oportunidades $\rightarrow$ terapia \\
\hline $\begin{array}{l}\text { - Habilidades académicas. } \\
\text { - Áreas de interés reducidas pero } \\
\text { obsesivas. Literalidad. } \\
\text { - Gran memoria mecánica por secuencias } \\
\text { establecidas. Rutinas } \\
\text { - Facilidades de memoria por hechos } \\
\text { concretos. }\end{array}$ & $\begin{array}{l}\text { - Aprenderán a ser más flexibles, al } \\
\text { sacarlos de su rutina y llevarlos al } \\
\text { yacimiento. } \\
\text { - Ayudarles a integrarse socialmente: } \\
\text { - Sus habilidades académicas y } \\
\text { su memoria mecánica serán } \\
\text { alagadas por sus compañeros. } \\
\text { · Los compañeros se adaptarán } \\
\text { a ellos. } \\
\text { - Creación de normas de actuación para } \\
\text { integrar emociones. }\end{array}$ \\
\hline
\end{tabular}

Figura 2: Análisis DAFO de las características generales del síndrome de Asperger.

Vemos en la Figura 1 que las tareas de "ordenar" y "catalogar" requieren las necesidades cognitivas de: capacidad de análisis, escribir, ordenar y trabajo independiente. Necesidades que para un alumno con Asperger están perfectamente cubiertas. Es más, se convierten en una oportunidad (y por tanto en una actividad terapéutica) porque son todos los elementos que suponen su fortaleza, como se puede ver en la Figura 2. Habilidades académicas, áreas de interés reducidas pero obsesivas, literalidad, gran memoria mecánica por secuencias establecidas, rutinas y facilidades de memoria por hechos concretos.

Inventario y catalogación de piezas arqueológicas, sería una tarea perfectamente realizable por un arqueólogo con síndrome de Asperger. Este mismo ejercicio se debería hacer de forma individual con cualquier persona, con o sin discapacidad. Al cruzar sus fortalezas con las necesidades cognitivas y físicas de la tarea arqueológica tendríamos como resultado la especialización arqueológica donde podrían potenciar sus capacidades.

Pero hay que tener en cuenta que algunas discapacidades también necesitan de un entorno físico que elimine barreras que permita realizar cualquier tarea arqueológica. Me refiero a la aplicación de estrategias de diseño para todos, para así crear las características accesibles que otorguen las garantías de calidad, comodidad y seguridad para cualquier usuario.

Esta cadena de la accesibilidad comienza en el entorno del yacimiento, en este caso, desde el punto de descarga de los alumnos en prácticas. Su objetivo principal es permitir la independencia del acceso a los alumnos con discapacidad. Para ello es necesario contemplar los distintos espacios en los que necesariamente deben considerarse estos principios de la accesibilidad.

Espacios como el entorno al yacimiento, donde hay que dotar del equipamiento necesario interno y externo en los edificios existentes. Tipos de pavimentos antideslizantes, picaportes ergonómicos y no enganchables para las puertas. Aparcamientos exteriores convenientemente señalizados. Senderos de acceso y desplazamiento al yacimiento.

Hay que aplicar pautas de accesibilidad física y ergonómica para lograr una circulación libre de obstáculos y el alcance y manipulación de los elementos que necesite cada persona. Hay que tener 
en cuenta aspectos ergonómicos y antropométricos según la diversidad humana de dimensiones, proporciones, condiciones de movilidad, fuerza o flexibilidad diversas.

Emplear dispositivos y tecnologías de apoyo a las personas con diversidad funcional. La tecnología adaptativa puede llegar a reducir el impacto de la discapacidad y satisfacer el derecho de la calidad de vida de las personas con necesidades especiales adecuando sus capacidades al entorno. En la Convención sobre los derechos de las personas con discapacidad (artículos 20 y $26)^{10}$, la resolución WHA58.23 de la Asamblea Mundial de la Salud ${ }^{11}$ y las Normas Uniformes sobre la igualdad de oportunidades para las personas con discapacidad ${ }^{12}$ se subraya la importancia de los dispositivos de apoyo.

En definitiva, hemos visto que la formación práctica arqueológica se imparte desde la universidad y que existen numerosas y diferentes tareas que se llevan a cabo en un yacimiento, susceptibles de ser realizadas por diferentes capacidades. Pero para que un yacimiento arqueológico sea accesible es necesario que disponga de un entorno sin barreras a través de la aplicación de pautas accesibles. Hasta donde alcanza mi investigación, dicha accesibilidad requiere de instalaciones permanentes para garantizar su uso por el mayor número posible de personas con discapacidad. Las administraciones invierten en la adecuación accesible de yacimientos arqueológicos para musealizarlos una vez han sido estudiados y que estén en situación de ser visitados por el total de la sociedad pero se carece de esta accesibilidad durante el proceso de excavación e investigación.

Es decir, hay que dotar a un yacimiento de la accesibilidad necesaria para que alumnos con y sin discapacidad puedan realizar sus prácticas para ser arqueólogos profesionales.

\section{La didáctica de la arqueología a personas con discapacidad: un reto para los profesionales}

En la actualidad universitaria es la buena voluntad del profesor quien da las respuestas necesarias al estudiante con diversidad funcional porque no existe una formación específica al profesorado para enseñar a alumnos con discapacidad, ni se les "motiva" de ninguna manera a dicha formación. La clave radica en ese cambio de concepción en el que se potencie y faciliten las herramientas necesarias. Existen propuestas para cambiar las reglas del juego, que sea la formación en atención a discapacidades lo que acumule créditos al profesorado, ésa sería la motivación y no la excelencia y la competitividad (González, 2011) que parece primar ante la docencia universitaria.

Hay incluso especialistas que recomiendan la formación en el ámbito de la discapacidad incidiendo en la enseñanza de criterios de accesibilidad e inclusión al patrimonio (Espinosa y Bonmartí, 2013) dentro de la docencia universitaria ya sea de grado o de posgrado, en estudios de arquitectura, ingeniería, los relacionados con la gestión del patrimonio, bellas artes o arqueología.

Son cada vez más habituales las experiencias didácticas practicadas en los IES que utilizan cada una de las tareas de una excavación arqueológica para enseñar los contenidos que integran el currículo de educación secundaria. No se distingue al alumnado por su capacidad sino por su interés y según los conocimientos arqueológicos. A modo de ejemplo y por ser de los más recientes publicados, comentar la experiencia llevada a cabo por el proyecto IES Arqueológico (Egea y Arias, 2013).

Pero al entrar en materia surge la pregunta ¿qué necesita un alumno con diversidad funcional para formarse como arqueólogo?

A nivel general se debe tratar al estudiantado de forma natural ya que la compasión y la sobreprotección pueden obstaculizar una relación adecuada. Un dato importante a tener en cuenta es que los alumnos están en la universidad por decisión propia, por tanto su visión del entorno puede ser más positiva que en estudios anteriores, aunque pueda arrastrar alguna experiencia de

10 Recuperado de: $h$ ttp://www.un.org/spanish/disabilities/default.asp?navid=13\&pid=497

11 Recuperado de: http://apps.who.int/gb/ebwha/pdf_files/WHA58-REC1/A58_2005_REC1-sp.pdf

12 Recuperado de: http://www.un.org/spanish/disabilities/standardrules.pdf 
abusos o marginación en su etapa formativa anterior que afecte negativamente a su desarrollo y autonomía.

Se deben fomentar las actitudes de participación, apoyo y aceptación. En el día a día del alumno con discapacidad son varios los factores que interactúan con él, tales como el personal de la universidad, los compañeros habituales del aula y sus propios profesores. Todos ellos necesitan de una orientación específica en temas de accesibilidad e inclusión para entender las necesidades del universitario con discapacidad y cómo responderlas. No se trata de que deban conocer cada casuística pero si de estar sensibilizados con normas básicas de atención y reacción. El apoyo específico debe ser cubierto por especialistas en cada materia, especialistas que también dispone cualquier universidad y por tanto no supone una inversión adicional.

Es necesario indicar que las discapacidades son relativas al individuo y a la situación, incluso lo normal es que puedan darse varias discapacidades en la misma persona, de ahí el término diversidad funcional. De hecho, los Asperger (TDH) no se diagnostican por porcentaje de discapacidad (al igual que la dislexia) y por tanto no disponen de apoyos reglados, sino que ambos son considerados a parte en los llamados ajustes razonables que se proporciona a los alumnos de forma individualizada por parte de los Centros de Apoyo al Estudiante de cada universidad.

El único objetivo debe ser el de potenciar las fortalezas del alumno para así minimizar las amenazas mediante la especialización de tareas arqueológicas. Que el docente pueda hacer llegar todo su conocimiento a los alumnos y en particular a los que tengan alguna discapacidad, depende en gran medida de su interés, como he comentado anteriormente, de su habilidad sobre el trato y del empleo de herramientas que ayuden a esta interacción.

En cuanto a la relación y el trato de personas con discapacidad quiero comentar brevemente aspectos que pueden considerarse de sentido común pero que creo necesario recordar. Por ejemplo en cuanto a un alumno con movilidad reducida:

- Se debe ser prudente con la invasión del espacio personal y el contacto físico. No sólo en cuanto a su cuerpo sino también por los productos de apoyo que pueda utilizar en su alrededor más inmediato (silla de ruedas, bastón, caminador, u otros objetos).

- Cuando cualquier persona hable con una persona con discapacidad, es necesario que se dirija directamente a ella y no a su asistente, acompañante o intérprete de lengua de signos.

- No hay que tomar decisiones que afectan a la persona con discapacidad sin haberla consultado previamente.

- Si es una persona usuaria de silla de ruedas, no se debe tocar su silla, ni empujar ni tampoco apoyarse. Si se tiene que ayudar a alguien en silla de ruedas a subir o bajar algún desnivel (escalón, bordillo, etc.), se debe preguntar antes cómo hacerlo porque se puede hacer caer la persona involuntariamente o desmontar partes de la silla si no se manipula correctamente. Se debe procurar hablar a la misma altura que la persona en silla de ruedas. Uno debe sentarse o alejarse para evitar que tenga que forzar el cuello para poder mantener el contacto visual.

- Si se trata de una persona usuaria de bastones o muletas, se debe tener prudencia con el contacto físico ya que puede perder el equilibrio con facilidad. Si se trata de una persona con limitaciones en la movilidad de sus manos, muñecas o brazos, se debe estar dispuesto a ofrecer ayuda en la apertura de puertas o en la manipulación de cualquier máquina o mecanismo.

Sobre las herramientas de apoyo al docente quiero hablar sobre la Lectura / Escritura Fácil porque es sencillo habituarse a ella y porque su uso beneficia a todos. Escribir bajo las directrices de la Lectura fácil significa facilitar la comprensión lectora no solo a personas con discapacidad intelectual, sino también a las que tienen problemas de aprendizaje independientemente de su inteligencia.

Estas directrices han sido redactadas por el Programa de acción en el ámbito del aprendizaje 
permanente de Inclusion Europe ${ }^{13}$. Las directrices de Lectura fácil indican diferentes pautas orientativas, entre las que sólo destacamos las siguientes:

- Utilizar frases cortas, con una sola idea y una estructura gramatical lógica y ordenada.

- Asociar imágenes a los textos.

- Usar un lenguaje sencillo y directo, lo que no significa infantil o banal. Uso de la segunda persona.

- Un lenguaje positivo y en voz activa.

- Evitar en lo posible el empleo del modo subjuntivo.

- Evitar las palabras largas, difíciles de leer o de pronunciar.

- Evitar las cifras numéricas largas o complicadas y subdividir el documento en párrafos breves.

La decisión de emplear estas formas habitualmente evitará el esfuerzo casual. No será algo mecánico que haya que pensar en cada ocasión. Una vez incorporado permanece en el día a día del arqueólogo.

\section{La dificultad de una divulgación / difusión no accesible}

"Para divulgar correctamente es necesario conocer bien un tema, saber cómo se construye la comunicación los mensajes divulgativos eficaces y por último desarrollar los mensajes con historias bien escritas y bien ilustradas" (Ruiz, 2009, p. 12). Hay que añadir, que también es necesario hacer los documentos con contenidos accesibles.

¿Por qué hay que escribir un artículo, un libro, hacer una presentación o un video con las pautas accesibles? Porque un documento escaneado, convertido en pdf, tiene formato digital pero su contenido no es accesible.

Primero, porque existe amplia legislación, internacional y nacional, sobre el derecho al acceso de información de las personas con discapacidad, como la dictada por La Convención de Derechos de las Personas con Discapacidad aprobada en la Asamblea General de la ONU en su artículo 9, 21 y 30, que entró en vigor el 3 de mayo de $2008^{14}$. También en España el Real Decreto Legislativo $1 / 2013$, de 29 de noviembre ${ }^{15}$ que se apoya en la Constitución Española y en la convención de la ONU anteriormente citada.

Segundo, porque en una divulgación el público espera la valiosa contribución de los arqueólogos responsables. Más cuando hablamos de la formación académica donde los alumnos con alguna discapacidad necesitan que esos contenidos estén generados bajo las directrices que sus productos de apoyo (línea braille, lectores de pantalla, lupas para ampliar el texto, ...) les permita interpretar todo lo que aparece (texto, imágenes, tablas..).

Tercero, porque la divulgación del conocimiento histórico es parte de las obligaciones de todo arqueólogo. Divulgar eficazmente es hacerlo pensando en todos los públicos utilizando las técnicas que beneficien a la totalidad. Aunque no se tenga una discapacidad legalmente reconocida, el empleo de pautas accesibles mejora la lectura y facilita el entendimiento del contenido independientemente de las limitaciones personales, tecnológicas o del entorno. Incapacidades transitorias, derivadas de la edad, inexperiencia tecnológica, idioma, cultura, nivel educativo o localización geográfica diferente.

13 Si desea consultar las directrices europeas para generar información de fácil lectura, puede hacerlo en El camino más fácil. Directrices europeas para generar información de fácil lectura de la Asociación Europea International League of Societies for Person with Mental Handicap (ILSMH). También existen guías para profesores. Recuperado de: http://www.sidar.org/recur/desdi/pau/directriceseuropeas\%20para\%20 facilitar\%20la\%20lectura.pdf

14 Recuperado de: www.ungs.edu.ar/ms_ungs/wp-content/uploads/2011/10/ConvencionLecturaFacil.pdf 15 Recuperado de: http://www.boe.es/boe/dias/2013/12/03/pdfs/BOE-A-2013-12632.pdf 
¿Qué hay que hacer para crear documentos electrónicos accesibles? Sólo hay que poner en práctica las directrices básicas para crear contenidos accesibles en documentos realizados desde procesadores de texto. Estas pautas siguen las prioridades 1 y 2 de la Norma UNE 139803:2004 basándose en las de Accesibilidad para el contenido web WCAG $2.0^{16}$.

- ¿Cómo usar el color correctamente?

- Emplear contraste de color entre el texto y el fondo ${ }^{17}$.

- No transmitir información sólo con el color. Añadir texto dentro.

- ¿Por qué tener en cuenta la tipografía?

- Tipo de fuentes San Serif (sin serifa), normal sin negrita.

- Tamaño de 12 a 14 puntos.

- Párrafos no justificados a la derecha para que la mirada distinga el siguiente párrafo.

- Interlineado 1,5 entre líneas y 2 entre párrafos.

- ¿Cómo mejorar la redacción de los textos?

- Las frases se deben componer de sujeto + verbo + predicado.

- Frases en positivo. Oraciones cortas, evitar subordinadas.

- Escribir un párrafo por idea.

- Emplear las listas para romper monotonía visual y de lectura.

- ¿Por qué se necesita de una buena estructura?

- Escribir títulos descriptivos, breves y concisos.

- Definirlos mediante estilos con la función específica del programa informático.

- ¿Cómo pongo un texto alternativo a la imagen?

- Si excede de 150 caracteres se utilizará un enlace explicativo.

- El texto del enlace debe ser explicativo de su función.

Cuánta "materia gris" continúa sepultada entre las paredes de los departamentos universitarios. Centros de investigación que no contemplan como algo prioritario su divulgación. Tesis doctorales, trabajos de fin de máster, trabajos de fin de grado que si en algún caso consiguen publicar un artículo en una revista, ni siquiera será bajo alguna de las directrices básicas aquí comentadas para que personas con discapacidad puedan acceder a ellas sin dificultad.

La transmisión del conocimiento arqueológico impartido desde la universidad debe adaptarse a directrices accesibles en beneficio de la propia arqueología.

\section{Reflexiones finales}

Hace unos años, numerosos profesionales de la arqueología comenzaron a detectar y a denunciar la insuficiente formación de los arqueólogos recién licenciados y graduados. Se denunció que las universidades españolas ofrecían una enseñanza arqueológica que se inscribía fundamentalmente dentro del título de Historia (Abad, 1995) y posteriormente comenzó a reclamarse un grado específico de arqueología (Ruiz, 2005). Los años de bonanza del sector de la construcción generaron mucha demanda de arqueólogos profesionales (Esquembre y Ortiz, 2001). En ese momento quedó patente el abismo entre la arqueología académica y la profesional (Gutierrez, 2011) y la necesidad de trabajar en equipo. Estudios académicos analizaron la actividad arqueológica profesional (Praga-Dans y Varela-Pousa, 2011) y recomendaron cambios a la hora de definir la

16 Es la última versión de las pautas de accesibilidad del contenido en la Web del World Wide Web Consortium (W3C). Fueron aprobadas el 15 de octubre de 2012 como estándar internacional ISO/IEC 40500:2012 Recuperado de: http://www.w3.org/TF/WCAG20/ traducción al español en http://www.sidar.org/traducciones/ wcag20/es/

17 Para comprobar los contrastes de color para que sean óptimos a daltónicos http://192.240.0.102/global/ accesibility/assistance/cd/ 
trayectoria formativa arqueológica.

Si se ha conseguido crear conciencia y lograr, en muchos casos, que la tradición académica arqueológica haya entendido la necesidad de continuar evolucionando para mirar y hacer suya la responsabilidad de crear arqueólogos capaces de ejercer la arqueología profesional o de campo, es también posible y más que necesario mirar a toda la sociedad en su conjunto. Quiero decir, dar un paso más y ver la formación didáctica y práctica arqueológica, estudiar en profundidad nuestra disciplina formativa en la que también se incluye a personas con alguna discapacidad.

Es momento de evaluar la forma o las cosas que hacemos para evolucionar a una arqueología excelente. Sí, supone un desafío. La divulgación y difusión del conocimiento arqueológico debe ser inclusivo. La formación de futuros arqueólogos no puede fallar.

Parece que disponemos de todas las herramientas necesarias. Una legislación internacional, nacional y autonómica que fomenta la necesidad de igualdad de oportunidades pero que le falta sancionar la falta de su cumplimiento y tampoco indica las pautas mínimas asumibles. Una "aparente" sensibilidad y voluntad política y social que ponga en práctica dicha legislación y vaya a más perfilando las necesidades reales de estos estudiantes. Finalmente unas universidades que facilitan el acceso a alumnos con discapacidad pero no facilitan los mecanismos y herramientas para su correcta formación ante el objetivo de su empleabilidad. Se necesitan nuevos planteamientos para que todo esto sea realidad.

En cuanto a la docencia, aquellos arqueólogos que tienen conciencia de la importancia de la transmisión del saber en su profesión ya se interesan, se implican hasta personalmente y consiguen "hacer", en ocasiones hasta de forma heroica. Pero a veces la falta de conocimiento o de motivación impide el uso de las sencillas herramientas que se han expuesto en este trabajo y que se pueden utilizar para facilitar su maestría. Sería bueno que desde las universidades se pongan en marcha mecanismos que cubran todas las necesidades que implican una formación íntegra en arqueología; es decir, que los docentes dispongan del personal y las herramientas de apoyo necesarias para que la cadena de la accesibilidad formativa quede completa. Que no sea una excepción aquellos docentes que se esfuerzan por formar inclusivamente. Si seguimos hablando de ello es porque además de voluntad hay que seguir haciendo cada día un poco más.

Y los otros, la minoría tradicional de la comunidad arqueológica que le cuesta evolucionar. Quizás son trabas impuestas por falta de conocimiento en sus propias capacidades y que para perjuicio de la formación y la arqueológica en general, imponen su limitada verdad.

Algunas de las preguntas que todos los arqueólogos debemos responder son ¿estoy transmitiendo mi conocimiento a la totalidad de la sociedad? ¿cómo puedo mejorarlo?.

Para la correcta evolución de la formación arqueológica es necesario que todos los factores sociales seamos capaces de aceptar la diversidad social para saber transmitir y para saber aprender de la diversidad de capacidades. Pensar en la globalidad y actuar localmente por el individuo porque afortunadamente la arqueología puede ser inclusiva.

\section{Bibliografía}

Abad, L. (1995). Arqueología, universidad e investigación. Actes de les Jornades d'Arqueologia (pp. 303-313). Valencia.

Egea Vivancos, A. y Arias Ferrer, L. (2013). IES Arqueológico. La arqueología como recurso para trabajar las competencias básicas en la educación secundaria. Clío. History and History teaching, 39. Recuperado de http://clio.rediris.es/n39/recursos/egeaarias.pdf

Esquembre Bebiá, M. A. y Ortega Pérez, J. R. (2001). Arqueología y empresa. Actas de las jornadas de arqueología y patrimonio alicantino (pp. 87-102). Alicante: Diputación Provincial de Alicante. Recuperado de http://dprha.ua.es/es/documentos/noticias/ii-jornadas-de-arqueologia-ypatrimonio-alicantino.pdf

Espinosa Ruiz, A. y Bonmatí Lledó, C. (2013). Manual de accesibilidad e inclusión en museos y lugares del patrimonio cultural y natural. Gijón: Ed. Trea. 
Everill, P. (2007). A day in the life of a training excavation: teaching archaeological fieldwork in the UK. World Archaeology, 39 (4), 483-498.

González Álvarez, D. (2013). Las“excavaciones de verano”: forjando superarqueólogos fácilmente precarizables. Arkeogazte, 3, 201-219.

González Rubial, A. (2011). El desastre académico de la arqueología. El futuro de la arqueología en España (pp. 99-104). Madrid: Jaime Almansa Sánchez (Ed.). Arqueología.

Gutiérrez Lloret, S. (2011). La arqueología ensimismada. El futuro de la arqueología en España (pp. 111-117). Madrid: Jaime Almansa Sánchez (Ed.).

Hillmann, K.-H. (2009). Diccionario Enciclopédico de Sociología. Barcelona: Ed. Herder.

Ruiz Zapatero, G. (2005). ¿Por qué necesitamos una titulación de arqueología en el siglo XXI? Complutum, 16, 255-269.

Ruiz Zapatero, G. (2009). La divulgación arqueológica: las ideologías ocultas. Cuadernos de Prehistoria y Arqueología de la Universidad de Granada, 19, 11-36.

Pérez Bueno L. C. (2010). Discapacidad, Tercer Sector e Inclusión Social. Comité Español de Representantes de Personas con Discapacidad, 47, 147-162.

Praga-Dans, E. y Varela-Pousa, R. (2011). Caracterización socioeconómica de la Arqueología Comercial española. Resultados de la primera encuesta nacional dirigida a empresas del sector. Complutum, 22 (1), 9-25.

Wing, L. (1981). Asperger's syndrome: a clinical account. Psychological Medicine, 11, 115-129. 



\section{Panta Rei}

PANTA REI es una revista digital de investigación orientada a la Historia y otras ciencias afines. Su principal objetivo es la transmisión del conocimiento científico, dando una oportunidad también a los jóvenes investigadores que quieren abrirse camino en el estudio de las ciencias humanas y sociales. Se compone de estudios originales relacionados con la disciplina histórica así como su didáctica y difusión. Las diferentes secciones que componen la revista son: artículos de investigación, entrevistas a profesionales, recensiones de monografías de actualidad y crónicas de congresos o eventos científicos relevantes.

Todos los artículos publicados son objeto de un proceso de revisión a cargo de un mínimo de dos evaluadores, que se consideran expertos en el ámbito temático del artículo propuesto. Nuestro deseo es poder ofrecer unos contenidos rigurosos, de calidad y de interés.

EI CEPOAT (Centro de Estudios del Próximo Oriente y la Antigüedad Tardía de la Universidad de Murcia) es la institución encargada de la coordinación y gestión de la revista, desde donde anualmente se lanzará la convocatoria para aquellos que estén interesados en publicar sus trabajos, siempre relacionados con la Historia, Arqueología, Historia del Arte, Didáctica de las Ciencias Sociales, etc.

PANTA REI is a digital journal focused on History and other sciences related to it. Its main objective is the transmission of scientific knowledge by giving also an opportunity to young researchers who want to make their way in the study of human and social sciences. It is composed by original studies related to History, as well as its didactics and promotion. The different sections of this journal are: research articles, interviews to professionals, recensions on monographs about current issues and reports about congresses or relevant scientific events.

All the articles published are subject to a revision process carried out by a minimum of two reviewers who are considered to be experts in the field of the article proposed. Our wish is to offer rigorous contents with quality and being of interest to the reader.

CEPOAT (Centre of Studies of the Middle East and Late Antiquity of the University of Murcia) is the institution in charge of the coordination and management of this journal. This is the centre from where the call for papers will be launched for all the people interested in publishing their papers, always related to History, Archeology, Art History, Didactics of the Social Sciences, etc. 


\section{Normas de Publicación}

El autor se compromete a enviar trabajos originales, que no se encuentren publicados en otras revistas ni en otros idiomas. Así mismo, el mismo artículo no podrá ser presentado en otras revistas mientras dure el proceso de evaluación.

\section{Envío y presentación de originales}

Los artículos se enviarán exclusivamente a través del correo electrónico a la dirección pantarei@um.es. Los textos serán enviados en formato DOC y las imágenes en formato JPEG o TIFF, y con un tamaño mínimo de 2000 px. Éstas no aparecerán incorporadas en el texto, sino enviadas en archivo aparte y correctamente numeradas según su posición en el texto. Junto al trabajo, se rellenará y enviará un documento aparte en el que se especifiquen los datos del autor siguiendo el modelo disponible en la página Web de la revista.

Para la redacción de los trabajos se tendrá en cuenta el Manual de la American Psychological Association, en su sexta edición. La extensión máxima de los trabajos será de 30 páginas. La tipografía será Arial 11, con interlineado sencillo y sin espacio alguno entre párrafos. El texto deberá ir justificado a ambos márgenes y sin sangría en los primeros párrafos. Los márgenes serán de $2,50 \mathrm{~cm}$. En los casos en los que fuera necesario incorporar notas, éstas irán a pie de página, enumeradas consecutivamente, con tipografía Arial 10, interlineado sencillo y justificadas a ambos márgenes.

Una información más detallada se encuentra disponible en la página http://www.um.es/cepoat/ pantarei.

\section{Proceso de valoración y evaluación}

Una vez recibidos los trabajos, la Revista realizará una primera valoración. Si el trabajo enviado se ajusta a las normas de presentación propuestas, la temática es coincidente con la línea editorial de la revista y posee la calidad científica necesaria, será remitido al consejo asesor para una primera evaluación. Si no es así en este primer paso se puede rechazar directamente los documentos que incumplan claramente la línea editorial.

Será el Consejo Asesor quien indique a la revista la originalidad, relevancia, estructura, redacción, aparato bibliográfico, etc. del trabajo enviado y, para ello, se designará a dos revisores expertos externos que evaluarán cada uno de los trabajos, que pueden formar parte (o no) de este Consejo Asesor. La selección de los revisores se ajustará a la temática y características metodológicas del trabajo. El nombre y filiación de los autores serán eliminados del trabajo para su revisión, así como los revisores actuarán de manera anónima y confidencial.

Los revisores deberán rellenar un informe de evaluación que centrará su atención en aspectos tales como características formales, originalidad y novedad de los trabajos, relevancia de las propuestas y los resultados, calidad metodológica y validez científica.

Una vez terminado el proceso se decidirá la aceptación o no de los mismos y su publicación en el número que sea pertinente, así como las modificaciones susceptibles de ser realizadas para su final publicación. Dicha notificación se enviará únicamente por correo electrónico, en un plazo máximo de seis meses. 


\section{Publishing rules}

The author is committed to submit original papers not having been published in other reviews or in other languages. In this way, it is not allowed for the same paper to be presented in other reviews during the evaluation process.

\section{Submission and presentation of originals}

The articles will be exclusively submitted by email to pantarei@um.es. The texts will be submitted in DOC format and the images in JPEG or TIFF format, and with a minimum size of 2000 px. Images will not be integrated in the text but sent in another file and properly numbered according to their position in the text. Attached to the paper, a document will be filled out and sent where the author's data will be specified following the model available on the website.

The sixth edition of the Manual of the American Psychological Association will be taken into account for the writing of the papers. The length of the papers must not exceed 30 pages. Typography will be Arial 11 , with simple line spacing and no space between paragraphs. The text must be justified on both margins without indentation in the first paragraphs. Margins size will be $2.50 \mathrm{~cm}$. Where it could be necessary the incorporation of notes, they will be at the bottom of the page, consecutively numbered with typography Arial 10, simple line spacing and justified on both margins.

More detailed information is available on the website: http://www.um.es/cepoat/pantarei.

\section{Examination and assessment process}

The Journal will submit the papers to a first examination once received. If the paper follows the presentation guidelines, the subject agrees with the editorial line of this journal, and possess the scientific quality required, it will be sent to the advisory council for a first assessment. If not, the documents which clearly fail to complete the editorial line may be rejected straightaway in this first step.

The Advisory Council will indicate the originality, relevance, structure, writing, bibliography, etc. of the text to the journal; for this purpose, two outside experts will be designated to review the papers; these experts can be (or not) part of this Advisory Council. The selection of the experts will adjust to the subject and methodological characteristics of the paper. Name and affiliation of the author will be eliminated from the text for its review, in this way experts will act anonymously and confidentially.

The experts will fill out an assessment report which will focus on aspects such as formal characteristics, originality and novelty of the papers, relevance and results of the proposal, methodological quality and scientific validity.

Once the process is finished, the acceptance or not of the papers and its publication in the corresponding edition will be decided, as well as the modifications that may be done for its final publication. This notification will be sent by email within 6 months maximum. 

